\title{
Prevalence \& Interventional Study of Vitamin D Deficiency in Adults working in Tertiary Care Hospital
}

\author{
Author \\ Dr Ashish Khurana \\ Diploma Ortho, PGIMS Rohtak, MD University \\ MS Ortho from MAHE Manipal \\ Senior Orthopaedic Surgeon ESIH Rohini
}

\begin{abstract}
Prevalence \& Interventional Study of Vitamin D Deficiency in Adults working in Tertiary Care Hospital

Keywords: Vitamin D deficiency in adults.
\end{abstract}

\section{Introduction}

Vitamin D structure developed by macullum in 1935. Full active metabolites and actions realised in $1970 \mathrm{~s}^{(1)}$.

This deficiency is endemic, sub-clinical and highly prevalent Normal being above 30ng/ml. 20-30-insufficient, and $<20$-deficient ${ }^{(2)}$.

Screening is possible by this study, all insufficient and deficient patients will be revealed, aptly treated and prophylaxis can be given.

In this study future symptoms and signs to develop are preventable. Most importantly pathological fractures are preventable to the extent of 5-10\%,, which occurs in its deficiency.

Early diagnosis and treatment can prevent vitamin D deficiency \& thus osteomalacia. Which is characterized by symptoms like proximal myopathy, muscle fatigue, mucle pains and tenderness, bone pains and tenderness, sweating, deformities in pelvis and spine, pathological fractures. ${ }^{(4)}$.
Remedial measures like mandatory fortification of dairy products like milk, vanaspati ghee, infant cereals and can be done through this study, like mandatory Iodination of salts was done and through the immunization programmes, like vitamin A prophylaxis was started with measles vaccine $^{(3)}$.

Negroes who have high melanin in their skin also need more sunlight exposure than white person to get the same amount of Vitamin $\mathrm{D}^{(3)}$.

Similarly an obese person also needs 5 times more exposure of sunlight to make the same vitamin D, compared to a normal person because the fatty (adipose) tissue in the obese person accumulates the Vitamin D and Doesn't allow it to show its affects in the blood because vitamin D is a "Fat soluble vitamin". ${ }^{(12)}$

\section{Aims and Objectives}

- To know the prevalence of Vitamin D deficiency in adults working in tertiary care hospitals in Mangalore 
- To know the signs, symptoms and Clinical features of these adult Vitamin D deficiency patients.

- To assess the Response of the treatment given to these patients.

\section{Materials \& Methods}

This study was undertaken with the objective of determining prevalence of Vitamin D deficiency in adults working in Tertiary care hospitals of Mangalore.

Study Design: Interventional study (both prospective and retrospective)

Period of Study: October 2012 to October 2013.

Population Studied: patients coming to department of orthopaedics \& other departments in tertiary care hospitals in Mangalore.

\section{Sample Size: 100}

Inclusion Criteria

1) Age above 18 years.

2) Bone pains, tenderness.

3) Muscle fatigue \& weakness.

4) Fibromyalgia like s/s. (pain \& tenderness in all 4 quadrants of body, right \& left-above \& below the waist)-like-low back, upper back ache, neck pain, muscle pains, etc.

\section{Exclusion Criteria}
1) Hereditary vitamin d resistant rickets/osteomalacia.
2) Renal rickets/osteomalacia.
3) Fancony's syndrome.
4) Crohn's disorder.
5) Coeliac syndrome.
6) Pathological fractures due other causes
like Osteoporosis, Osteopetrosis, osteogenesis imperfecta etc.

\section{Method in Detail}

Estimation of Vitamin D Assay (25 (OH) Hydroxy levels by Electro- cheminoluminiscence immunoassay technique. In this technique a chemical kit is obtained \& 100 samples can be tested by seeing the change in colour by adding chemicals which gives a "luminescence" and thus estimation of exact levels is done with respect to the luminescence produced by the chemicals on reacting with the patient's blood sample..

\section{Steps}

1) Sample mixed and incubated with ReagentDithiothreitol.

2) Again Pre-Treatment and incubation with 2 nd Reagent-Sodium Hydroxide done.

3) Streptavidin-coated microparticles are added with Biotin-a 'COMPLEX' is formed.

4) This "Complex' mixture is aspirated into the measuring cell where the microparticles are magnetically captured onto the Electrode. Application of voltage to the electrode PRODUCES CHEMILUMINISCENCE EMISSION which is measured by a PHOTOMULTIPLIER.

5) Final results are estimated by a calibration curve by 2-point calibration and a master curve provided by the reagent barcode.

Other methods of estimation of vitamin D (25 HYDROXY LEVELS) are-

1) Fluoroimmunoassay.

2) Radio immunoassay.

3) Elisa.

\section{Statistical Analysis}

Data analysis will be done by using Students Paired ' $T$ ' test and Chisquare test

PROBABILITY-P $<0.05$ will be considered as significant

A statistical package for social sciences (SPSS) Version 11.5 will be used to do this analysis.

\section{Review of Literature}

Vitamin D is also called "SUNSHINE VITAMIN" or "VITAMIN DENTRIQUTICA". (1).

Vitamin D Prevents Proliferation of Keratinocytes \& cells in Prostrate, Breast \& Ovaries. through its action on vitamin D Receptors (VDRS).

The vitamin D Deficient Patients are more prone to Cancers of gonads (testes, ovaries), prostrate, breasts, skin and uterus etc. ${ }^{(5) .(6)(13)}$.- Chandrakant chakraborti et al-

Induction of vitamin D leads to death of cancer cells both in-vivo and in-vitro. 
Vitamin D decreases Angiogenesis-this deprives cancer cells of its blood supply. Thus prevents their growth and spread. This it does by suppressing IL-8-which stimulates angiogenesis thus providing oxygen and nutrition to cancer cells-Vitamin D Prevents this..

Vitamin D when acts on Vitamin D Receptors (VDR), regulates 80 genes which are antiproliferative and anti-metastatic. It also inhibits cancer growth factors which cause cancer cell growth arrest.

E-cathedrins are calcium dependent adhesion molecules which inhibit cancer progression and metastasis by increasing 'cellular adhesions'. This is controlled by vitamin $\mathrm{D}$.

Gene-Cst5-codes for formation of Cystadin Dwhich down regulates the Tumorogenesis inColon, Ovaries and Breast Cancers. This is caused by Vitamin D actions on Vdrs.

Vitamin D Increases 'Apoptosis' - thus causing Tumour Growth Attenuation-Proved in breast, ovaries tumours.

All these anti-cancer actions of vitamin $\mathrm{D}$ are seen on chronic administration of vitamin D-2000 4000 UNITS/DAY. Sunlight exposures to high levels is also advised to such patients.

Vitamin D Deficient Patients are more prone to Diabetes Mellitus(10),

In this study, which was a Prospective observational study - details regarding — diet, Bm.i. index, blood sugar levels, obesity task force criteria data, etc. were used.

Insulin Resistance was calculated by Computer Based Model-Homeostasis Assessment Model (HOMA-IR) which utilized Fasting Blood Sugar and Fasting Serum Insulin Levels.

The whole body Insulin Sensitivity was measured by-MATSUDA AND DEFRONZO INDEX.

There was a significant inverse relation found with Vitamin D Levels and Insulin-Resistance. This is to do with similarity in Vitamin D Receptors and Receptors Associated wim Insulin Secretion and its Actions..
The Lower Vitamin D Level Cases had Increased Insulin Resistance- Thus Increased Type 2 Diabetes.

To see the Effect of Vitamin D \& it's Effect on Calcium Utilization in the Body one can do" SULKOWITCH TEST"-24 HOURS URINE CALCIUM ESTIMATION TEST (normal being 100 - 250 ML/ day) (11). Qamar khan supplemented vitamin D deficient individuals with 1000-4000 units/day.

He deduced that more the supplementation less was the calcium in urine output of the individual - thus indicating vitamin D function of absorption and utilization of vitamin D. Barring Kidney Disease Patients-The Results of Vitamin D Supplementation were Directly Proportional to the Results and oved the 'SULKOWICH TEST'VALID.

Osteomalacia can lead to Muscle Fatigue, Stress, Bone Pains, Bone Tenderness, Weakness, Proximal Myopathy \& Pathological Fractures. ${ }^{(4)}$, (14)

By giving Calcitriol (Active Synthetic Form of Vitamin D), One can treat these Features. Alternatively Alpha-Calcidol which Activates in Liver \& does not need Activation in Kidney or the Enzyme 1-Alpha-Hydroxylase this is specifically mentioned in pharmacotherapy book by Dr. K.D. Tripathi $^{(1)} \&$ they have concluded that "these drugs can be given in Kidney Disorders also, where the Activating enzyme-1-alpha hydroxylase is deficient'.

Cholecalciferol Injections, Tablets \& Satchels can be given with Milk \& Calcium Supplements to overcome the Deficiency State of Vitamin D in Adults-Osteomalacia. ${ }^{(1)}$ (11).

This study is suggestory to the Govt. to make it Mandatory that all Infant Cereals. Vanaspathi Ghee \& Juices, Milk products and Cereals ete. to be Fortified with Vitamin D,.

Vitamin D Levels: $100 \mathrm{ng} / \mathrm{m}$---maximum body toleration. $60 \mathrm{ng} / \mathrm{ml}$---optimum desired-adultlevels.

Toxicity-levels $>150 \mathrm{ng} / \mathrm{ml}$. (Hypercalcemia, calcium-stones formation in urine, etc.) 
$>30 \mathrm{ng} / \mathrm{ml}=$ normal for metabolic normal adult bones.

$20-30 \mathrm{ng} / \mathrm{ml}=$ insufficient level.

$<20 \mathrm{ng} / \mathrm{ml}=$ deficient levels.

10 to $20 \mathrm{ng} / \mathrm{ml}=$ mild deficiency

5 to $10 \mathrm{ng} / \mathrm{ml}=$ moderate deficiency

$<5 \mathrm{ng} / \mathrm{ml}=$ Severe deficiency
This list to secondary rise of parathormone levels. Which also can't act due to deficiency of substrate 25 hydroxy levels.

Thus active levels of 1,25 di-hydroxy levels of vitamin $\mathrm{D}$ not formed therefore decreased bone mineralization \& decreased serum calcium levels which can lead to "Tetany" (7) (12).

\section{Analysis and Results}

Age

\begin{tabular}{|l|c|c|c|c|c|}
\hline & $\mathrm{N}$ & Minimum & Maximum & Mean & Std. Deviation \\
\hline AGE & 100 & 18 & 80 & 35.59 & 14.161 \\
\hline
\end{tabular}

The average age of this study was 35.59 years. Range was from $18-80$ years

Sex

\begin{tabular}{|l|c|c|}
\hline & Frequency & Percent \\
\hline $\mathrm{F}$ & 64 & 64.0 \\
$\mathrm{M}$ & 36 & 36.0 \\
Total & 100 & 100.0 \\
\hline
\end{tabular}

There are 64 females and 36 Males in this study

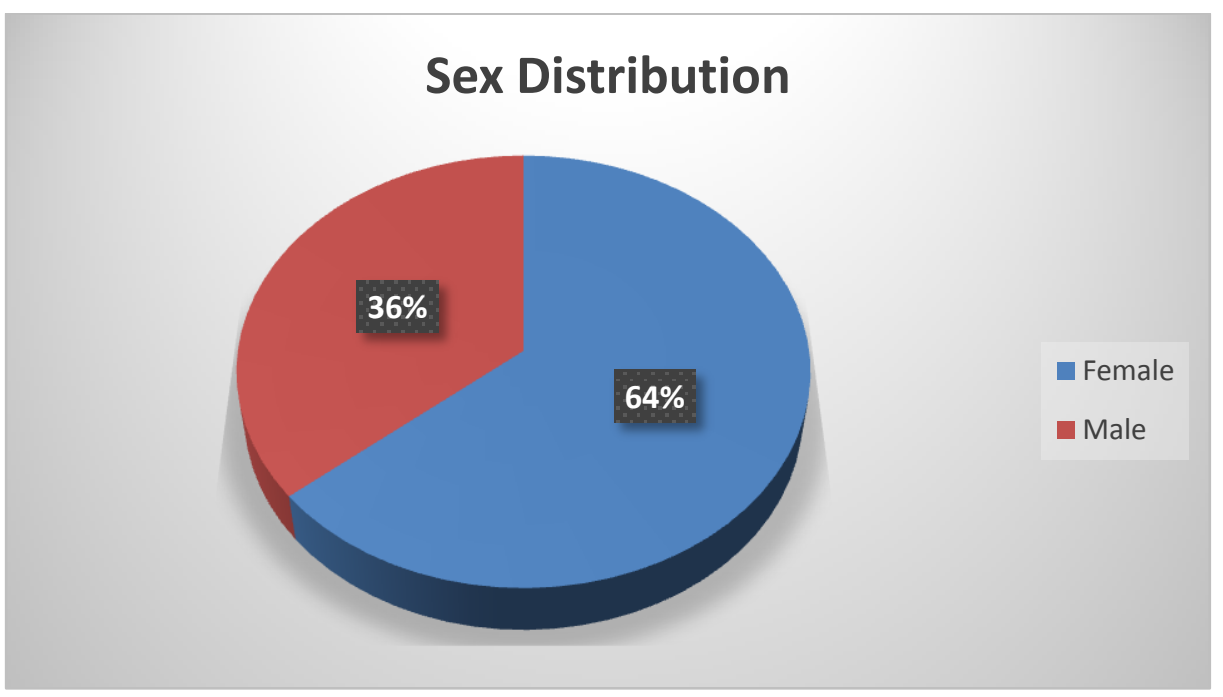

\section{Occupation}

\begin{tabular}{|l|c|c|}
\hline & Frequency & Percent \\
\hline TEACHER & 2 & 2.0 \\
PROFESSOR & 21 & 21.0 \\
PG & 11 & 11.0 \\
NURSE & 19 & 19.0 \\
INTERN & 13 & 13.0 \\
CLERK & 8 & 8.0 \\
WORKERS & 7 & 7.0 \\
STUDENT & 19 & 19.0 \\
Total & 100 & 100.0 \\
\hline
\end{tabular}

There are 2 teachers, 21 professor, 11 postgraduate students, 19 nurses, 13 interns, 8 clerks, 7 worker \& 19 students in this study totalling - 100 . 


\section{OCCUPATION STATUS}

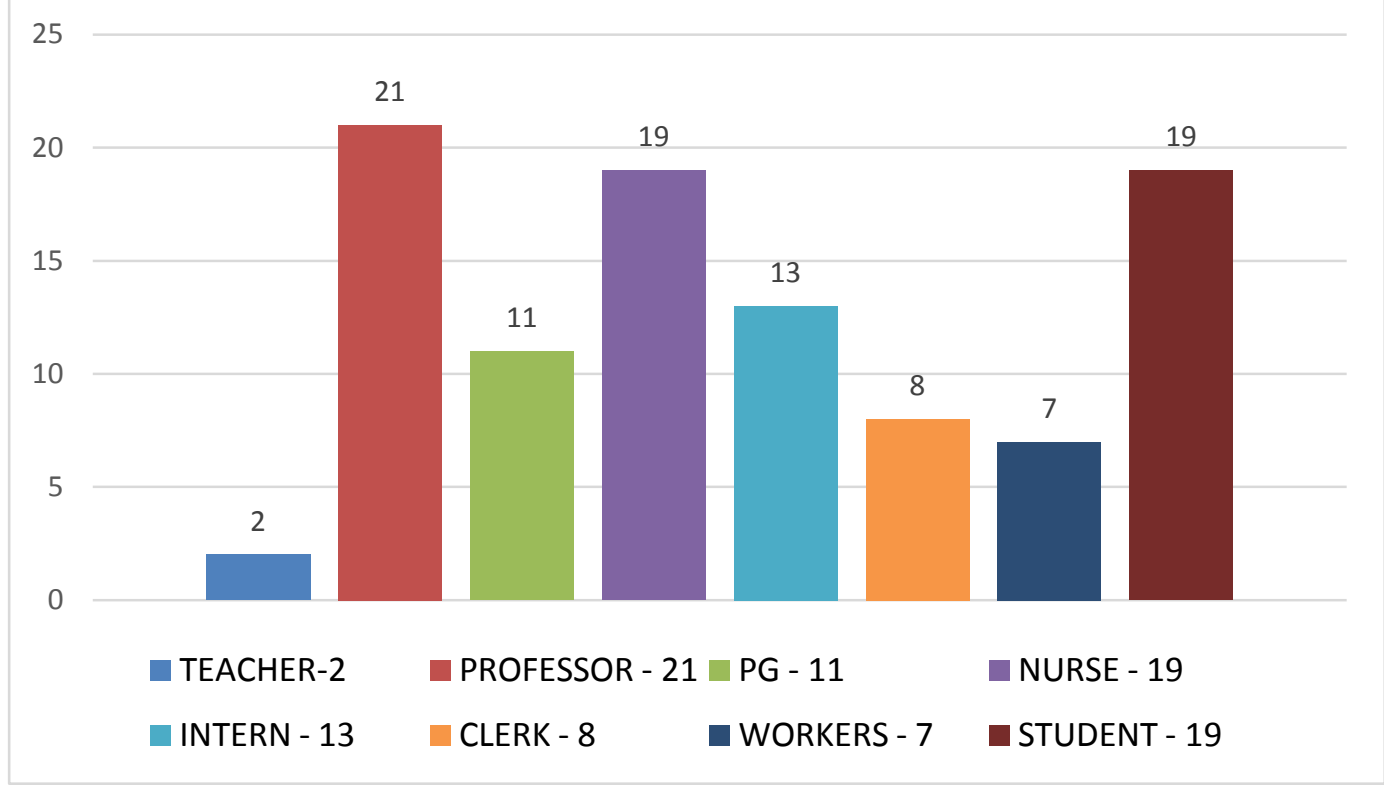

\section{Religion}

\begin{tabular}{|l|c|c|}
\hline & Frequency & Percent \\
\hline & & \\
BUDDHIST & 1 & 1.0 \\
CHRISTIAN & 16 & 16.0 \\
HINDU & 73 & 73.0 \\
MUSLIM & 9 & 9.0 \\
SIKH & 1 & 1.0 \\
Total & 100 & 100.00 \\
\hline
\end{tabular}

Religion wise data shows above where $73 \%$ of respondents are Hindus and $16 \%$ are Christians.

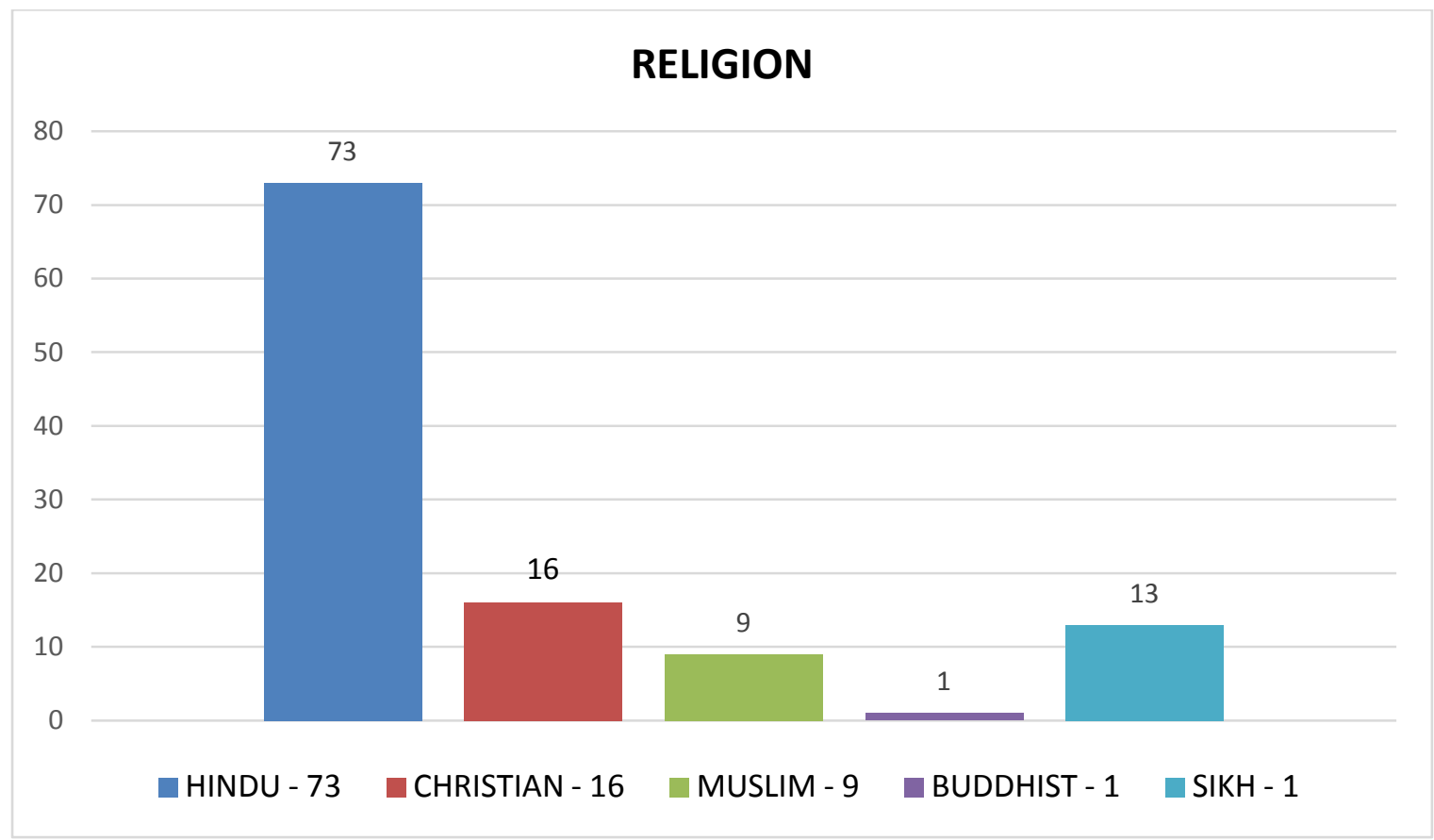




\section{JMSCR Vol||07||Issue||04||Page 1136-1147||April}

Diet

\begin{tabular}{|l|c|c|}
\hline & Frequency & Percent \\
\hline MIXED & 65 & 65.0 \\
NONVEG & 8 & 8.0 \\
VEG & 27 & 27.0 \\
Total & 100 & 100.00 \\
\hline
\end{tabular}

There are 65 mixed dieters, 8 non - veg dieters \&

All normal tested 7 were of mixed \& non - veg 27 veg dieters in this study. diet. rest all deficient were max. from veg. diet group, then mixed \& min. from non-veg. group.

BMI

\begin{tabular}{|l|c|c|c|c|c|}
\hline & $\mathrm{N}$ & Minimum & Maximum & Mean & Std. Deviation \\
\hline BMI & 100 & 16.98 & 35.75 & 23.2981 & 3.97518 \\
\hline
\end{tabular}

Their average BMI index was 23.2981. The range was from 16.98 to 35.75 .

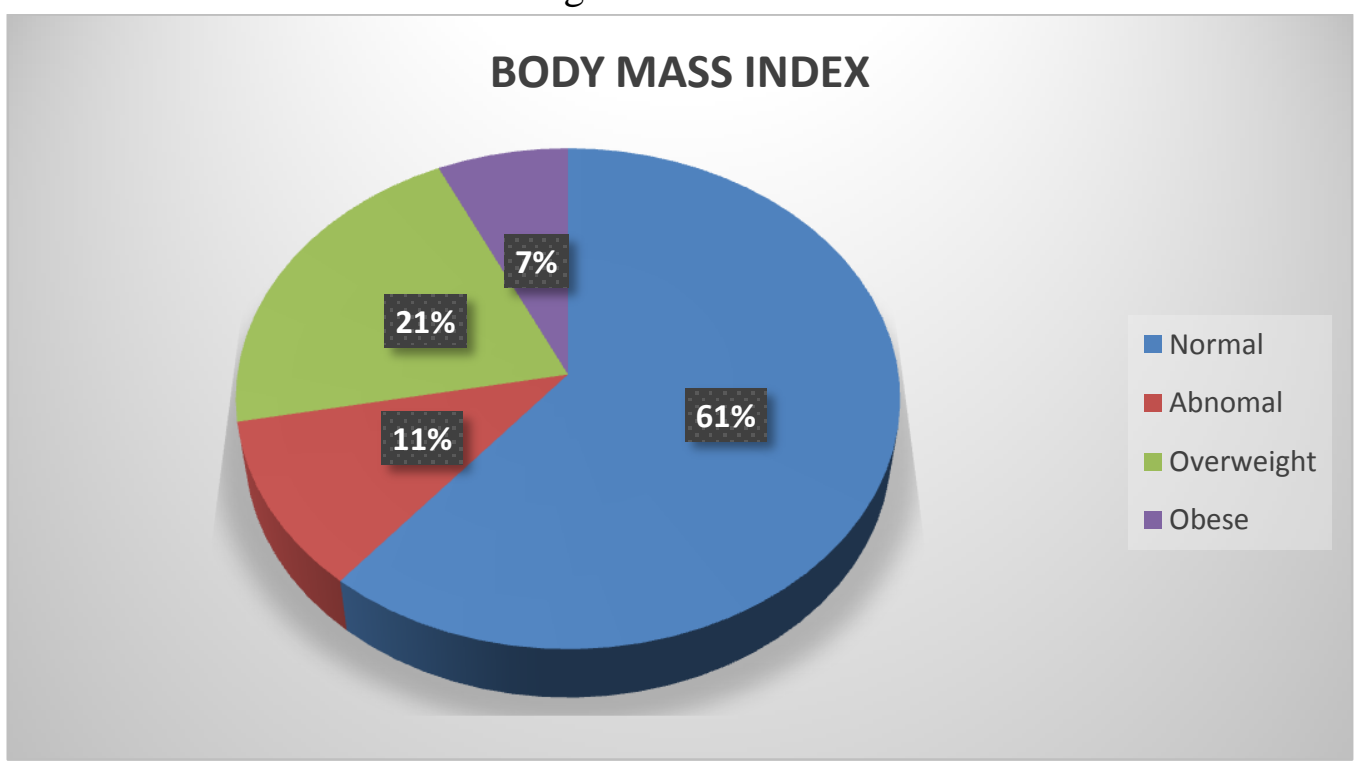

\section{Exercise Schedule}

\begin{tabular}{|l|c|c|}
\hline & Frequency & Percent \\
\hline NIL & 57 & 57.0 \\
1HR/WK & 2 & 2.0 \\
2HRS/WK & 7 & 7.0 \\
3HRS/WK & 8 & 7.0 \\
4HRS/WK & 6 & 6.0 \\
6HRS/WK & 3 & 3.0 \\
7HRS/WK & 8 & 8.0 \\
10HRS/WK & 2 & 2.0 \\
14HRS/WK & 2 & 2.0 \\
20HRS/WK & 3 & 3.0 \\
4 DAY/WK & 1 & 1.0 \\
YOGA-4/WK & 1 & 1.0 \\
Total & 100 & 100.00 \\
\hline
\end{tabular}

There were 57 patients with no exercise schedule on any daily basis. 8 were the max people found to do exercise for $3 \mathrm{hrs}$ and $7 \mathrm{hrs} / \mathrm{wk}$. 


\section{Sunlight Exposure}

\begin{tabular}{|l|c|c|}
\hline & Frequency & Percent \\
\hline NIL & 4 & 4.0 \\
$<30$ minutes & 59 & 59.0 \\
30-60 minutes & 26 & 26.0 \\
$>1$ hour & 11 & 11.0 \\
Total & 100 & 100.0 \\
\hline
\end{tabular}

\section{SUNLIGHT EXPOSURE}
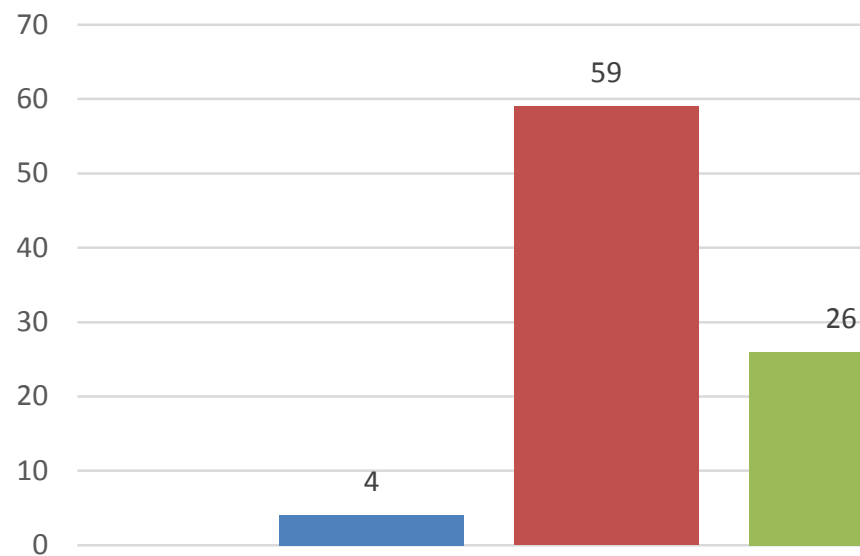

NIL - $4 \quad \square 30$ MINUTES - $59 \square$ 30-60 MINUTES - $26 \square>1$ HOUR - 11

\section{Vitamin D Deficiency vs BMI}

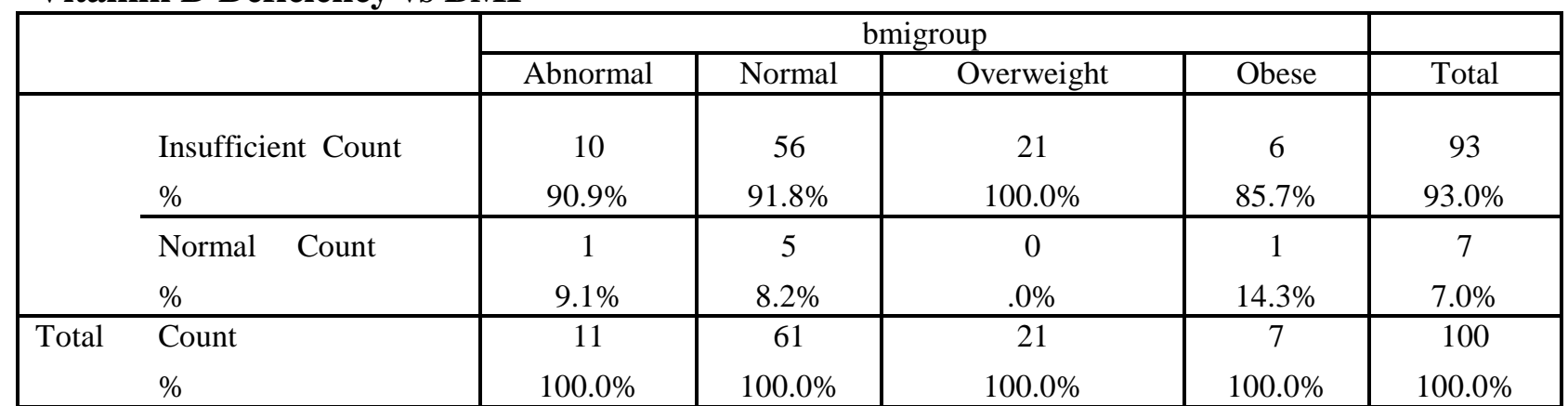

cases 21 were insufficient and 0 were normal. In abnormal bmi cases -10 were insufficient and Finally, in obese 6 were insufficient and 7 were normal insufficient and 5 were normal, in overweight

DIET VS VIT D DEFICIENCY

\begin{tabular}{|l|c|c|c|c|}
\hline \multirow{2}{*}{} & \multicolumn{3}{|c|}{ DIET } & \multirow{2}{*}{ Total } \\
\cline { 2 - 5 } Insufficeint Count & MIXED & NONVEG & VEG & 93 \\
$\%$ & 62 & 7 & 24 & $93.0 \%$ \\
\hline Normal Count & $95.4 \%$ & $87.5 \%$ & $88.9 \%$ & 7 \\
\\
$\%$ & 3 & 1 & 3 & $7.0 \%$ \\
\hline Total Count & $4.6 \%$ & $12.5 \%$ & $11.1 \%$ & 100 \\
\hline
\end{tabular}




\section{JMSCR Vol||07||Issue||04||Page 1136-1147||April}

In mixed dieters 52 were insufficient and 3 were normal. In veg. dieters 24 were insufficient and 3 were normal. Finally, in non- veg 7 were insufficient and 1 was normal.

Vitamin D Deficiency vs Sun Exposure

\begin{tabular}{|ll|c|c|c|c|c|}
\hline & \multicolumn{5}{|c|}{ SUNEXPOSURE } & \\
\cline { 3 - 7 } & & Nil & $\begin{array}{c}<30 \\
\text { minutes }\end{array}$ & $30-60$ minutes & $>1$ hour & Total \\
\hline befvit & Insufficeint Count & 4 & 55 & 23 & 11 & 93 \\
& $\%$ & $100.0 \%$ & $93.2 \%$ & $88.5 \%$ & $100.0 \%$ & $93.0 \%$ \\
\hline & Normal Count & 0 & 4 & 3 & 0 & 7 \\
& $\%$ & $.0 \%$ & $6.8 \%$ & $11.5 \%$ & $.0 \%$ & $7.0 \%$ \\
\hline Total & Count & 4 & 59 & 26 & 11 & 100 \\
& $\%$ & $100.0 \%$ & $100.0 \%$ & $100.0 \%$ & $100.0 \%$ & $100.0 \%$ \\
\hline
\end{tabular}

$\mathrm{X}^{2}=1.956 \mathrm{p}=0.582 \mathrm{~ns}$

\section{Exercises vs Vit D Deficiency}

\begin{tabular}{|c|c|c|c|c|c|c|}
\hline & \multicolumn{4}{|c|}{ EXERCISES } & \multirow[b]{2}{*}{ Total } \\
\hline & & Nil & $<3 \mathrm{HR}$ & 3-6 HR & $>6 \mathrm{RH}$ & \\
\hline & Insufficeint Count & 56 & 10 & 12 & 15 & 93 \\
\hline & $\%$ & $96.6 \%$ & $90.9 \%$ & $92.3 \%$ & $83.3 \%$ & $93.0 \%$ \\
\hline & Normal Count & 2 & 1 & 1 & 3 & 7 \\
\hline & $\%$ & $3.4 \%$ & $9.1 \%$ & $7.7 \%$ & $16.7 \%$ & $7.0 \%$ \\
\hline Total & Count & 58 & 11 & 13 & 18 & 100 \\
\hline & $\%$ & $100.0 \%$ & $100.0 \%$ & $100.0 \%$ & $100.0 \%$ & $100.0 \%$ \\
\hline
\end{tabular}

In nil exposure $100 \%$ were insufficient. in $<30$ minutes exposure /day -55 were insufficient and 4 were normal. In 30-60 minutes, exposure /day 23 were insufficient and 3 were normal. Finally in $>1$ hour exposure/day -11 were insufficient and 0 was normal.

$\mathrm{X}^{2}=3.791 \mathrm{p}=.285 \mathrm{~ns}$
In nil exercisers 56 were insufficient and 2 were normal. In $<3$ hours exerciser 10 were insufficient and 1 was normal. In 3-6 hours exercisers $=12$ were insufficient and 1 was normal, finally in > 6hours exercisers 15 were insufficient and 3 were normal.

\section{Prior to Treatment with Vitamin D}

\begin{tabular}{|l|c|c|}
\hline & Frequency & Percent \\
\hline Insufficient & 93 & 93.0 \\
Normal & 7 & 7.0 \\
Total & 100 & 100.0 \\
\hline
\end{tabular}

There were only 7 people who were tested normal before Intervention study.

$11(11.827 \%)$ were found 'insufficient' \& 82 (88.172\%) were found 'deficient'. 


\section{JMSCR Vol||07||Issue||04||Page 1136-1147||April}

\section{After Treatment with Vitamin D}

\begin{tabular}{|l|c|c|}
\hline \multirow{3}{*}{ Insufficient } & Frequency & Percent \\
\cline { 2 - 3 } Normal & 56 & 60.2 \\
Total & 37 & 39.8 \\
& 93 & 100 \\
\hline
\end{tabular}

\section{VIT-D CONSUMPTION}

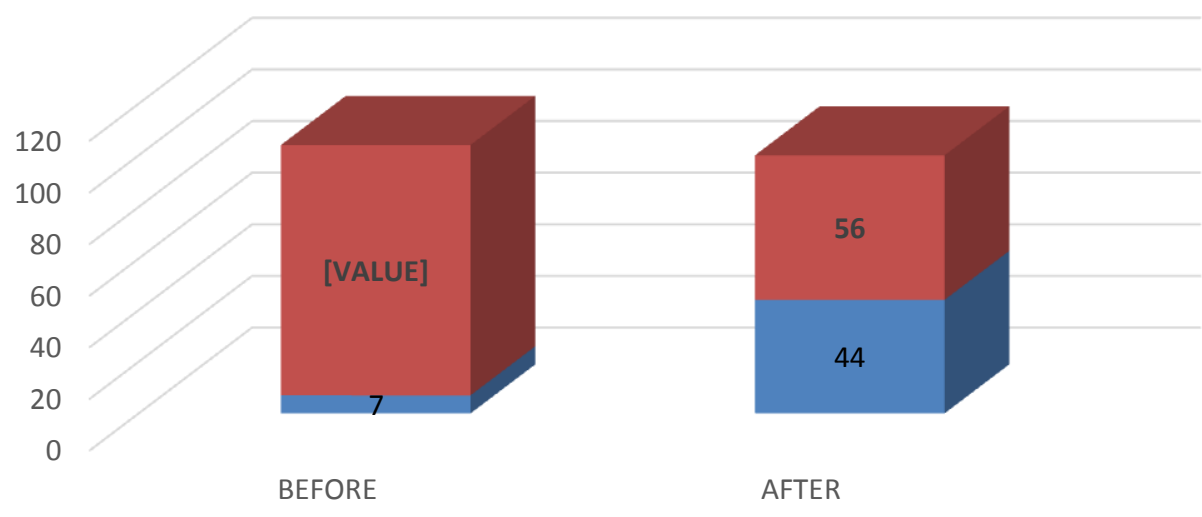

- Insufficient

After Vitamin D Intervention $39.8 \%$ of people became normal

Paired Samples Statistics

\begin{tabular}{|l|c|c|c|c|}
\hline & $\mathrm{N}$ & Mean & Std. Deviation & Std. Error Mean \\
\cline { 2 - 5 } B.VIT D & 93 & 14.0584 & 6.43862 & 0.66409 \\
After & 93 & 29.1944 & 16.78626 & 1.73137 \\
administrating & & & & \\
VIT D & & & & \\
\hline
\end{tabular}

\section{Paired Samples Test}

\begin{tabular}{|l|c|c|c|c|}
\hline & \multicolumn{2}{|c|}{ Paired Differences } & & \multirow{2}{*}{} \\
\cline { 2 - 4 } & Mean & Std. Deviation & $\mathrm{t}$ & $\mathrm{P}$ \\
\hline B.VIT D - A VIT D & -15.13596 & 17.99393 & -8.155 & $<.001 \mathrm{vhs}$ \\
\hline
\end{tabular}

There was a significant improvement in study cases (patients) after Vitamin D administration to values pf $\mathrm{P}<.001$ vhs (very highly significant) in them as is seen by the probability significance the chart table above.

\section{Comparison of before and after Administering Vitamin D - Sex Wise}

Paired Samples Statistics

\begin{tabular}{|ll|c|c|c|c|}
\hline SEX & & $\mathrm{N}$ & Mean & Std. Deviation & Std. Error Mean \\
\hline Male Pair 1 & \multirow{2}{*}{ B.VIT D } & 33 & 13.5126 & 6.23531 & 1.06935 \\
A VIT D & & 33 & 27.5947 & 12.68657 & 2.17573 \\
\hline Female Pair 1 & \multirow{2}{*}{ B.VIT D } & 60 & 14.3677 & 6.58261 & .84981 \\
A VIT D & & 60 & 30.1008 & 18.75705 & 2.42153 \\
\hline
\end{tabular}


Paired Samples Test

\begin{tabular}{|lc|c|c|c|c|}
\hline \multirow{2}{*}{ SEX } & \multicolumn{2}{|c|}{ Paired Differences } & \multirow{2}{*}{} & \multirow{2}{*}{} \\
\cline { 3 - 4 } & Mean & $\begin{array}{c}\text { Std. } \\
\text { Deviation }\end{array}$ & $\mathrm{t}$ & $\mathrm{P}$ \\
\hline Male & B.VIT D - A VIT D & -14.08206 & 14.09658 & -5.825 & .000 \\
\hline Female & B.VIT D _ A VIT D & -15.73317 & 19.95545 & -6.107 & .000 \\
\hline
\end{tabular}

There was considerable improvement in female cases compared to male cases after vitamin D administration as seen in the chart table above.

Pain being the main symptom\& fatigue a close second were found to be decreased in cases whose vitamin D levels increased after administering vitamin $D$. thus a marked improvement in symptoms after treatment with vitamin D took place.

\section{Discussion}

This study was undertaken with the objective of evaluating the prevalence of Vitamin D deficiency in adult patients working in tertiary care hospitals in Mangalore.

For this "PREVALANCE STUDY" of Vitamin D was done. it found mat among the sample of 100 patients out of which 64 were female patients and 36 were male patients.

Out of this many were professor /staff, students, Nurses, clerks, PGs and Workers. Out of them only seven were tested normal that is they equal or above $30 \mathrm{ng} / \mathrm{ml}$ of Vitamin D Assay in their body. Thus more than $93 \%$ were found to be insufficient $(11.827 \%)$ or deficient $(88.172 \%)$. Many of them were associated with Fibromyalgia like symptoms \& signs. Some were associated with Diabetes Mellitus, Hypertension, Skin Disease and Gonadal (Testes, Ovaries), Prostrate, etc. Cancers. (43\% with pain and fatigue, $25 \%$ cases with diabetes, $20 \%$ with hypertension, $10 \%$ with skin disorders, $2 \%$ with cancers of ovaries, breasts, digestive system and prostrate etc.

Most common symptoms of was of pain and 2nd commonest was fatigue (43\%) which was maximum in the low back area, upper back, both knees, shoulders, ankles, and multiple joint pains. Also many suffered wim Muscle pains as in Calves, shoulder and back muscles.
Many of the patients had nil (4\%) or very little exercise schedule daily.

Many of the patients had very little sunlight exposure.

$4 \%$ nil \& 59\% less than 30 minutes/day.

After interventional study it was found that there was about $40 \%$ improvement in the case studies initial Vitamin D levels and there Symptoms also improved increasedly esp. -Pain, from severe to moderate $\&$ from moderate to mild levels.

The case studies who didn't take the treatment of Vitamin D administration orally / injectibly, seriously and didn't adhere to the diet regimen and taking proper sunlight didn't improve --------- due improper intake. (61.22\%).

The results were better in females than males, as can be seen by the Probability significant values in the sex comparison charts. Females had low bmi, better exercise, better sunlight exposure \& were more serious \& compliant to the treatment regimen given to them.

The overall result of the INTERVENTIONAL STUDY OF VITAMIN D was an overall success with Probability significant value less than 0.001 VHS. (VERY HIGHLY SIGNIFICANT).

\section{Conclusion}

From this comprehensive study of 100 samples case study following conclusions are drawn.

- The sunlight exposure is the most important provider of natural Vitamin D. To the extent that 5-10 minutes exposure of head, neck, face per day can give us 20,000 units of Vitamin D which cannot be obtained by DIET or $\operatorname{DRUGS}^{(8),(9)}$.

- The Vitamin D obtained from nonveg diet is more potent than that obtained from vegetarian diet. on experimental studies on 
animals in the 'absorption of calcium' from gut $^{(12)}$.

- Alteration of lifestyles, diet intakes, proper sunlight exposure can joinedly bring about decrease in the prevalence of this high vitamin D from the society.

- Just like govt. has made VITAMIN A DROPS COMPULSARY WITH EVERY MEASLES VACCINATION.(3)-national immunization programme (nip) in 2000 goals of immunization by Indian govt.

- Govt. help is also needed to 'fortify food products with vitamin D.' Just like govt. has made IODINATION OF ALL SALTS MANDATORY, by realizing the deficiency of iodine, esp.in underground waters \& hilly areas (3) - and made salt iodination mandatory in it's 'Food fortifacation' programmes.

- Public Awareness programmes regarding high prevalence of this Vitamin D deficiency WILL HELP IN ITS RSDUCTION IN SOCIETY-BY COMBINED EFFORTS OF INDIVIDUALS AND GOVT..

- Lifestyle modifications of individuals especially who are aged and non ambulatory should be communicated properly. By tv media, posters, cable, newspapers, radio (fm) etc.

- Thus we can conclude that by the efforts of individuals and govt. we can remove this deficiency and the complications associated with it from the society.

\section{Bibliography}

1. K.D. Tripathi- Pharmacology

2. Harrison - Book of Medicine

3. Park \& Park - community medicine

4. Mercer - Orthopaedics

5. Edward Giovannucci, Yan Liu, Eric rim prospective study of predictors of Vitamin D status \& cancer incidence \& mortality

6. Chandrakant Chakarborty - Vitamin D as an effective anti- cancer agent- Indian Journal of Pharmacology
7. J.J Canell, Hollis, Zasloff --- diagnosis \& treatment of Vitamin D deficiency - Expert opinion Pharmacother

8. Michael.F.Holick, Neil Binkley, Heilke Bischoff - evaluation, treatment \& prevention of Vitamin D deficiency Boston univ.school of medicine --- journal clinics endocrinal metabolism

9. Tangpricha, Pearce, Chen \&Holick Prevalence of Vitamin D deficiency in healthy adults - the American journal of medicine

10. Teresa Martin, Keith Campbell - Vitamin D \& Diabetes - Pharmacy \& Therapeutics Diabetes spectrum.

11. Qamar .J.Khan, MD, Carol Fabian, Kansas medical center - how to treat vitamin D deficiency - American society of clinical oncology.

12. Vin Tangpricha, MD, Elizabeth Pearce, Tai Chen - Vitamin D insufficiency among free living healthy young adults - skin \&bone research lab. - Boston, Massachusetts

13. Cedric Garland, Frank Garland, Edward Gorham - The Role of Vitamin D in Cancer Prevention---American Journal of Public Health

14. John Ebnezar - Orthopaedics

15. T. R. Bandgari, N.S Shah - Vitamin D and Pathological hip fractures -Journal of association of Physicians of India

16. Nidhi Malhotra, Ambrishmittal - Vitamin D Status in asia - Journal of Association of Physicians of India (japi)

17. Mary Brophy marcus - Adults still risk Vitamin D deficiency - Usa Today

18. Thomas roesel, MD - Adult Vitamin D deficiency - Review of literature and implications for force health protection

19. Nawafmutairi, Bayoumi Ibrahim---Photo protection and Vitamin D status - A study on awareness, knowledge and attitude towards sun protection in general population from Kuwait and its relationship 
with Vitamin D levels - Indian journal of dermatology

20. C.V Harinarayan, T. Ramalaxmi - Vitamin D status in Andhra Pradesh: A Population based study - Indian journal of medical research

21. Marc drezner, MD, --Patient information (beyond the basics) - Literature current review

22. Jordan lite -Vitamin D deficiency soars in the Usa - Scientific American

23. Afsanehtalaei, Nasrinyadegari - Prevalence of Vitamin D deficiency among adult secondary students of Arak, Iran in 2010 Indian journal of Endocrinology and metabolism

24. Daniel Donovan, AnastasiopapadoulosBone mass and Vitamin D deficiency in adults with advanced cystic fibrosis lung disease -Columbia university, new York American journal of respiratory and critical care medicine

25. Sunil kumar, Siva Krishna kota - Reninangiotensin system activity in Vitamin D deficient individuals with Hypertension; An urban Indian study --- Indian journal of Endocrinology and metabolism. 